\title{
DESAIN DAN PENGUJIAN KAPASITAS INSTALASI POMPA PENYEDIA AIR BERSIH DI KAMPUS POLITEKNIK KOTABARU
}

\author{
Mochamad Bastomi \\ Prodi Teknik Mesin, Politeknik Kotabaru \\ Jalan Raya Stagen Km. 9,5 Kotabaru Kalimantan Selatan \\ Email:m.bastomi09@gmail.com
}

\begin{abstract}
ABSTRAK
Letak geografis gedung Kampus Politeknik Kotabaru dengan ketinggian $44 \mathrm{~m}$ dari ketinggian pipa induk Perusahaan Daerah Air Minum (PDAM) setempat dan jarak sekitar $433.2 \mathrm{~m}$ dari jangkauan pipa induk tersebut serta kondisi instalasi pompa air bersih di kampus tersebut yang kurang memadai dalam penyediaan air bersih mengakibatkan persediaan air bersih mengalami kekurangan.

Penelitian untuk mengetahui desain instalasi pompa dan kapasitas instalasi pompa hasil desain agar mencukupi kebutuhan persediaan air bersih di kampus tersebut. Metode yang digunakan dengan menghitung kebutuhan air bersih, head total instalasi, dan pompa dituangkan dalam gambar layout instalasi. Setelah pemasangan dilanjutkan pengujian kapasitas aliran. Diperoleh instalasi pompa dengan pipa instalasi panjang $433.2 \mathrm{~m}$ diameter $0.0127 \mathrm{~m}$ (0.5 in), 1 unit meteran air tipe turbine-wheel, 6 unit elbow $90^{\circ}$ diameter $0.0127 \mathrm{~m}(0.5 \mathrm{in}), 2$ unit check valve diameter $0.0127 \mathrm{~m}(0.5 \mathrm{in})$ dan 2 unit gate valve diameter $0.0127 \mathrm{~m}$ (0.5 in), 2 unit pompa dengan head total $59,5 \mathrm{~m}$ dan kapasitas $0,6-4,5 \mathrm{~m}^{3} / \mathrm{h}$ untuk pompa I dan head total $60 \mathrm{~m}$ kapasitas $4,5 \mathrm{~m}^{3} / \mathrm{h}$ untuk pompa II yang disusun secara seri. Kapasitas aliran instalasi pompa $0.6361\left(\mathrm{~m}^{3} / \mathrm{h}\right)$ hingga $1,0008\left(\mathrm{~m}^{3} / \mathrm{h}\right)$.
\end{abstract}

Kata Kunci : head, pompa, kapasitas aliran, instalasi

\section{PENDAHULUAN}

Air adalah sumber daya alam yang mutlak diperlukan bagi kehidupan manusia dan dalam sistem tata lingkungan, air adalah unsur lingkungan. Kebutuhan manusia akan kebutuhan air selalu meningkat dari waktu ke waktu, bukan saja karena meningkatnya jumlah manusia yang memerlukan air tersebut, melainkan juga karena meningkatnya intensitas dan ragam dari kebutuhan akan air. (Silalahi, 2002).

Letak geografis gedung Kampus Politeknik Kotabaru dengan ketinggian $44 \mathrm{~m}$ dari ketinggian pipa induk Perusahaan Daerah Air Minum (PDAM) setempat dan jarak sekitar $433.2 \mathrm{~m}$ dari jangkauan pipa induk tersebut serta kondisi instalasi pompa air bersih di kampus tersebut yang kurang memadai dalam penyediaan air bersih mengakibatkan persediaan air bersih mengalami kekurangan dan bahkan harus membeli langsung dengan mobil tangki air minum.

Penelitian ini bertujuan untuk mengetahui desain instalasi pompa dan kapasitas instalasi pompa hasil desain sehingga mampu mencukupi kebutuhan persediaan air bersih di kampus tersebut.

\section{METODE PENELITIAN}

Adapun tahapan kegiatan penelitian guna mencapai tujuan yang telah ditetapkan, melalui langkah-langkah sebagai berikut:

a) Tinjauan lapangan 
Kegiatan ini dilakukan dengan cara peninjauan lapangan untuk melakukan pengamatan secara langsung dan melakukan pengukuran secara langsung mengenai panjang keseluruan pipa dari sumber sampai pada tempat penampungan dengan mengunakan roll meter, perbedaan ketinggian tanah dari sumber sampai pada penampungan dengan GPS, mengukur diameter dalam pipa dengan jangka sorong.

b) Tinjauan pustaka

Kegiatan ini dilakukan dengan cara mengumpulkan sumber informasi referensi yang berkaitan dengan desain yang akan dibahas dari buku, jurnal ilmiah baik media cetak maupun elektronik.

c) Proses desain instalasi pompa penyediaan air bersih dengan melakukan perhitungan kebutuhan air bersih, perhitungan head total yang terdiri dari head statis, head losses, head beda tekanan, head kecepatan aliran, serta melakukan pemilihan pipa beserta sambungan pipa instalasi yang digunakan dan pompa, divisualisasikan dalam gambar desain instalasi pompa.

d) Proses pemasangan instalasi.

e) Pengujian kapasitas aliran air dengan alat ukur water meter dan gelas ukur serta stop watch.

\section{HASIL DAN PEMBAHASAN}

A. Perhitungan Kebutuhan Air

Data jumlah mahasiswa aktif dan dosen di Politeknik Kotabaru 372 orang. Jadi pemakaian air dapat di hitung dengan persamaan berikut:

Kapasitas = Jumlah Pemakai $\times$ Jumlah Pemakaian

$$
\begin{aligned}
& =372 \times 40 \\
& =14880 \text { liter/hari } \\
& =14,88 \mathrm{~m}^{3} / \text { hari } \\
& =0,62 \mathrm{~m}^{3} / \mathrm{h}
\end{aligned}
$$

Dalam desain ini didesain kapasitas instalasi pompa $1 \mathrm{~m}^{3} / \mathrm{h}$ sebagai antisipasi jika ada penambahan mahasiswa pada tahun berikutnya.

B. Perhitungan Head Total

\section{Head Statis Pompa}

Beda tinggi geometris tanah mulai dari sumber sampai pada penampungan adalah $44 \mathrm{~m}$, maka $\mathrm{h}_{\mathrm{a}}=44 \mathrm{~m}$.

2. Beda Tekan

$$
\begin{aligned}
\Delta \mathrm{h}_{\mathrm{p}} & =\mathrm{h}_{\mathrm{p} 2}-\mathrm{h}_{\mathrm{p} 1} \\
\Delta \mathrm{h}_{\mathrm{p}} & =0-0 \\
& =0 \mathrm{~m} .
\end{aligned}
$$

Karena pada tempat penampungan air adalah tangki terbuka dan pada sisi hisap diasumsikan tekanan air dari pipa induk PDAM pada titik terendah nol pada tekanan ukur.

3. Head Losses

a. Kerugian head pada pipa (major losses)

Luas penampang dalam pipa dengan diameter dalam pipa $16.50 \mathrm{~mm}$ $(0.0165 \mathrm{~m})$

$$
\begin{aligned}
A & =\frac{3,14}{4} \times 0,0165^{2} \mathrm{~m}^{2} \\
& =0,00021371625 \mathrm{~m}^{2} .
\end{aligned}
$$

Maka kecepatan aliran fluida dalam pipa yang digunakan dalam modifikasi desain:

$$
\begin{aligned}
V & =\frac{0,000278\left(\mathrm{~m}^{3} / \mathrm{s}\right)}{0,00021371625\left(\mathrm{~m}^{2}\right)} \\
& =1.30079(\mathrm{~m} / \mathrm{s}) .
\end{aligned}
$$

Untuk mengetahui berapa harga koefisien gesek yang terjadi dalam pipa, maka dapat diketahui dengan mengunakan rumus dari persamaan 5 maka :

$$
\operatorname{Re}=\frac{\rho V d}{\mu}
$$

Di mana 
$\mu=$ Viskositas dinamis air pada suhu $25^{\circ} \mathrm{C}$ adalah $0.887 \times 10^{-3}(\mathrm{~kg} / \mathrm{m} . \mathrm{s})$

$\rho=$ Kerapatan air pada suhu $25^{\circ} \mathrm{C}$ adalah 997,97 ( $\mathrm{kg} / \mathrm{m} . \mathrm{s})$

[Abdul

Makhsud, 2012 :9 ]

Maka :

$\operatorname{Re}=24148,2131$

Karena nilai $\mathrm{Re}$ lebih besar dari 4000 berarti aliran turbulen maka untuk nilai faktor gesek pipa

$$
f=0.02535
$$

Dengan persamaan 6 diperoleh head losses dalam pipa sepanjang $433.2 \mathrm{~m}$ sebesar $57.39755 \mathrm{~m}$.

b. Kerugian head pada sambungan dan katup (minor losses).

Kerugian head pada sambungan yang terdiri dari 6 unit elbow $90^{\circ}, 1$ unit water meter tipe turbine-wheel, 2 unit check valve, 2 unit gate valve dengan nilai $k$ sambungan sesuai Tabel 1 diperoleh nilai $k$ total

$\sum k=6 k_{\text {elbow }}+k_{\text {water meter }}+2 k_{\text {check-valve }}$ $+2 k_{\text {gate valve }}$

$\sum k=(6 \times 0.8)+6+(2 \times 2.5)+(2 \times 0.2)$ $=16.2$

$$
\begin{aligned}
h_{\text {minor }} & =16.2 \times \frac{1,30079^{2}(\mathrm{~m} / \mathrm{s})}{2 \times 9,81\left(\mathrm{~m}^{2} / \mathrm{s}\right)} \\
& =1.3971 \mathrm{~m}
\end{aligned}
$$

Sehingga diperoleh head losses total

$$
\begin{aligned}
\mathrm{h}_{l} & =\mathrm{h}_{f}+\mathrm{h}_{\text {minor }} \\
& =58.79 \mathrm{~m} .
\end{aligned}
$$

4. Head kecepatan

Menurut dari rumus persamaan 16 head kecepatan dapat diketahui dengan persamaan.

$$
\begin{aligned}
\mathrm{h}_{k} & =\frac{1.30079^{2}}{2 \times 9.81}-\frac{0^{2}}{2 \times 9.81} \\
& =0.086 \mathrm{~m} .
\end{aligned}
$$

Diperoleh head total

$$
\begin{aligned}
\mathrm{H} & =44+0+58.79+0.086 \\
& =102.876 \mathrm{~m} .
\end{aligned}
$$

Diperoleh desain instalasi pompa dari pipa instalasi panjang $433.2 \mathrm{~m}$ dengan diameter $0.0127 \mathrm{~m}$ (0.5 in), meteran air (water meter) tipe turbinewheel sebanyak 1 unit, elbow $90^{\circ}$ diameter $0.0127 \mathrm{~m}$ (0.5 in) sebanyak 6 unit, katup cek (check valve) diameter $0.0127 \mathrm{~m}$ (0.5 in) sebanyak 2 unit dan katup pintu (gate valve) diameter $0.0127 \mathrm{~m}$ (0.5 in) sebanyak 2 unit, 2 unit pompa dengan head total $59,5 \mathrm{~m}$ dan kapasitas $0,6-4,5 \mathrm{~m}^{3} / \mathrm{h}$ untuk pompa I dan head total $60 \mathrm{~m}$ kapasitas $4,5 \mathrm{~m}^{3} / \mathrm{h}$ untuk pompa II yang disusun secara seri untuk memenuhi kebutuhan akan air bersih di Kampus Politeknik Kotabaru.

Setelah dilakukan pemasangan instalasi pompa, kemudian dilakukan pengujian dengan hasil pengujian kapasitas aliran dengan water meter sesuai hasil pada Tabel 2 .

Tabel 2. Hasil pengujian kapasitas aliran dengan menggunakan water meter.

\begin{tabular}{|c|c|c|c|}
\hline No & $\begin{array}{c}\text { Volume } \\
\left(\mathrm{m}^{3}\right)\end{array}$ & $\begin{array}{c}\text { Waktu } \\
(\mathrm{s})\end{array}$ & $\begin{array}{c}\text { Debit } \\
\left(\mathrm{m}^{3} / \mathrm{s}\right)\end{array}$ \\
\hline 1 & 0.057 & 300 & 0.000190 \\
\hline 2 & 0.0448 & 300 & 0.000149 \\
\hline 3 & 0.0605 & 300 & 0.000201 \\
\hline 4 & 0.053 & 300 & 0.000176 \\
\hline 5 & 0.0518 & 300 & 0.000172 \\
\hline 6 & 0.0531 & 300 & 0.000177 \\
\hline 7 & 0.0509 & 300 & 0.000169 \\
\hline 8 & 0.0529 & 300 & 0.000176 \\
\hline 9 & 0.0533 & 300 & 0.000178 \\
\hline 10 & 0.0536 & 300 & 0.000179 \\
\hline
\end{tabular}




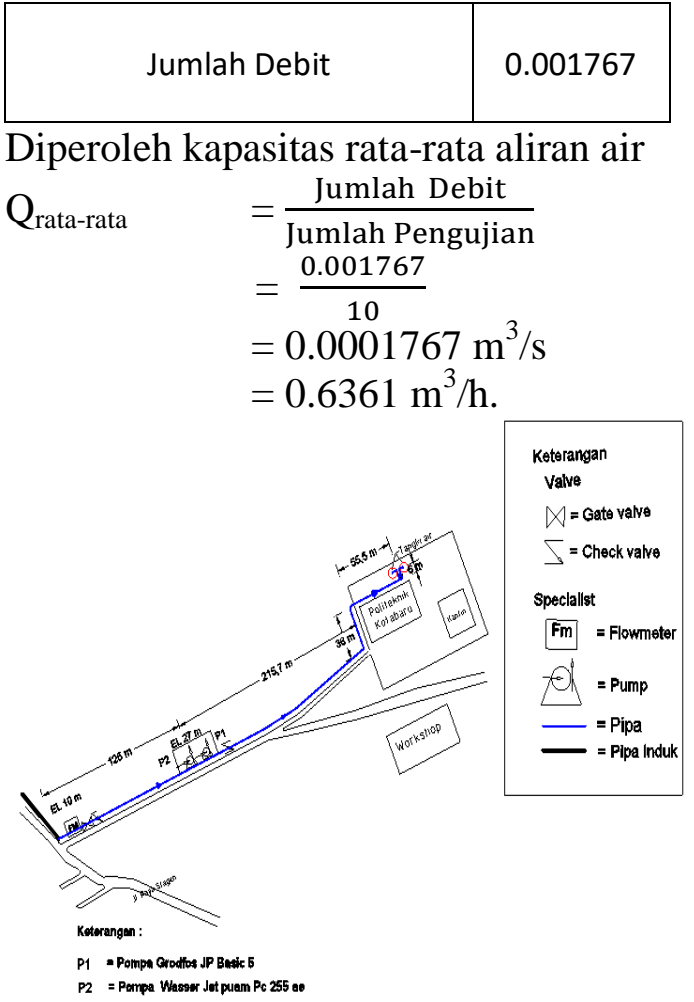

Gambar 4. Layout instalasi pompa di Kampus Politeknik Kotabaru.

Sedangkan pengujian dengan gelas ukur dengan mengisi drum yang dengan volume $0.15 \mathrm{~m}^{3}$ memerlukan waktu selama 540 detik, sehingga diperoleh kapasitas aliran pemompaan sebesar $0.0002778 \mathrm{~m}^{3} / \mathrm{s}$ atau $1.0008 \mathrm{~m}^{3} / \mathrm{h}$.

Berdasarkan hasil pengujian diperoleh kapasitas aliran instalasi pompa penyedia air bersih di Kampus Politeknik Kotabaru sebesar $0.6361 \mathrm{~m}^{3} / \mathrm{h}$ hingga $1.0008 \mathrm{~m}^{3} / \mathrm{h}$, telah sesuai spesifikasi selang kapasitas aliran pompa I antara 0.6 hingga $4.5 \mathrm{~m}^{3} / \mathrm{h}$ dan mampu memenuhi kebutuhan air bersih rencana.

\section{KESIMPULAN}

Berdasarkan

pembahasan diperoleh kesimpulan sebagai berikut:

1. Desain instalasi pompa yang terdiri dari pipa instalasi panjang $433.2 \mathrm{~m}$ dengan diameter $0.0127 \mathrm{~m}$ (0.5 in), 1 unit meteran air (water meter) tipe turbine-wheel, 6 unit elbow 90 diameter $0.0127 \mathrm{~m}$ (0.5 in), 2 unit katup cek (check valve) diameter $0.0127 \mathrm{~m}$ (0.5 in) dan 2 unit katup pintu (gate valve) diameter 0.0127 $\mathrm{m}$ (0.5 in), 2 unit pompa dengan head total 59,5 $\mathrm{m}$ dan kapasitas 0,6 $-4,5 \mathrm{~m}^{3} / \mathrm{h}$ untuk pompa I dan head total $60 \mathrm{~m}$ kapasitas $4,5 \mathrm{~m}^{3} / \mathrm{h}$ untuk pompa II yang disusun secara seri.

2. Kapasitas aliran instalasi pompa $0.6361 \quad\left(\mathrm{~m}^{3} / \mathrm{h}\right) \quad$ hingga 1,0008 $\left(\mathrm{m}^{3} / \mathrm{h}\right)$.

\section{REFERENSI}

[1] Tahara, H. \& Sularso 2000. Pompa dan Kompresor: Pemilihan, Pemakaian dan Pemeliharaan. Jakarta: Pradnya Paramita

[2] Silalahi, M. D., 2002, Optimalisasi Sarana Yuridis Sebagai Upaya Menumbuhkan Masyarakat Sadar Urgensi Sumber Daya Air (SDA), Majalah Air Minum, Edisi No. 97 / th. XXIII Desember 2002.

[3] Saksono, P. 2010. Analisis Efisiensi Pompa Centrifugal pada Instalasi Pengolahan Air Kampung Damai Balikpapan.(Online), (http://comingout.hol.es/analisisefisiensi-pompa-centrifugal-padainstalasi-pengolahan-air-kampungdamai-balikpapan/, diakses 10 Agustus 2016)

[4] Artayanaa, K.C.B. dan Atmaja, G.I. 2010, Perencanaan Instalasi Air Bersih Dan Air Kotor Pada Bangunan Gedung Dengan Menggunakan Sistem Pompa. Jurnal Ilmiah Teknik Mesin Vol. 4 No.1. April 2010 (51-56). Hal. 2-3

[5] Fritz, Dietzel 1980, Turbinen, Pumpen, Und Verdichter, Jakarta; Erlangga

[6] Hariyono, F.R. dan Djoni, I.M.A. 2013, Perancangan Pompa Slurry Sentrifugal Pada Unit Cement Mixer Yang Mendukung Operasi Kerja Ulang Sumur Dengan Kapasitas 3,5 bpm Dan Head 30 Feet (Studi Kasus di PT. Energi Mega Persada Tbk). Jurnal Teknik Pomits Vol. 2, No. 1, (2013). Hal. 2 
[7] Makhsud, A. 2012, Mekanika Fluida, Teori dan Aplikasi, Kretakup Print. Fakultas Teknik UMI Makassar

[8] Tukiman dkk. 2013, Perhitungan Dan Pemilihan Pompa Pada Instalasi Pengolahan Air Bebas Mineral Iradiator Gamma Kapasitas 200 kci. Prosiding Pertemuan Ilmiah Perekayasaan Perangkat Nuklir PRPN - BATAN, 14 November 2013. Hal. 3 \& 5

[9] Zulkifli, Harahap. 1996, Pump Application Engineering, Jakarta; Erlangga

[10] Rossman, L.E. 2000. Epanet 2 Users Manual. U.S. Environmental Protection Agency.

[11] Information on https://neutrium.net/fluid_flow/press ure-loss-from-fittings-excess-head-kmethod/ 